University for Business and Technology in Kosovo

UBT Knowledge Center

Nov 1st, 2:00 PM - 2:15 PM

\title{
Symbolism and Poetics of Autogenic Space and Structures - The New Design Approach on Mosque as Representative Building (Design Proposal for the Central Mosque of Prishtina as Case Study)
}

Banush Shyqeriu

University for Business and Technology, banush.shyqeriu@ubt-uni.net

Kushtrim Hajdari

Hoppe Architekten, arch.kushtrimhajdari@hotmail.com

Follow this and additional works at: https://knowledgecenter.ubt-uni.net/conference

Part of the Architecture Commons

\section{Recommended Citation}

Shyqeriu, Banush and Hajdari, Kushtrim, "Symbolism and Poetics of Autogenic Space and Structures The New Design Approach on Mosque as Representative Building (Design Proposal for the Central Mosque of Prishtina as Case Study)" (2013). UBT International Conference. 1.

https://knowledgecenter.ubt-uni.net/conference/2013/all-events/1

This Event is brought to you for free and open access by the Publication and Journals at UBT Knowledge Center. It has been accepted for inclusion in UBT International Conference by an authorized administrator of UBT Knowledge Center. For more information, please contact knowledge.center@ubt-uni.net. 


\title{
Symbolism and Poetics of Autogenic Space and Structures - The New Design Approach on Mosque as Representative Building (Design Proposal for the Central Mosque of Prishtina as Case Study)
}

\author{
Banush Shyqeriu ${ }^{1}$, Kushtrim Hajdari² \\ ${ }^{1}$ Lecturer at Faculty of Architecture, University for Business and Technology in Prishtina; \\ Researcher at Institute for Cultural Sciences, Humboldt University in Berlin \\ banush.shyqeriu@ubt-uni.net \\ ${ }^{2}$ Architect at Hoppe Architekten, Vienna; PhD Candidate at Vienna University of Technology \\ arch.kushtrimhajdari@hotmail.com
}

\begin{abstract}
The congregation Mosque, Masjid (from Arabic, sujúd = prostration to God) is one of the most important institutions of Muslim world, also the predominant built form of Mus lim architecture. Having a basic spatial configuration to create "shelter" for prayer, it is evoking how the simple space bears meaning that generates symbolism. This paper tries to de-construct and re-construct the Mosque as a representative built form. By using our Design Proposal for the Central Mosque of Prishtina as Case Study, we emphasize an "organic" approach towards Mosque design through a methodology of integral contextualization and conception as the new "typology", by re-interpreting the traditional symbolic repertoire of structural and spatial elements / grammar of Mosque, towards novel spatial scenarios and narratives in the realm of phenomenology of architecture. Generating meaning which connects the tradition and contemporary perception is the ultimate goal of this approach, aside a higher spatial, structural and energetic performance of the Mosque as built form.
\end{abstract}

Keywor ds: Mosque; "shelter"; meaning; symbolism; design; "organic"

\section{Introduction}

Human beings are bound, attracted and "rooted" to certain places and spaces not for their mere formal expression or aesthetics, but for their meanings they hold, elicit and convey to them, which meanings provide a comprehensive mutual communication between the user and natural environment as well as with built forms and build environments.

Buildings do elicit meanings, and at this point architecture reconciles itself with the user it "shelters". Yet, modern built forms and environments have frequently lost the phenomena of meaning, as they do not belong to us to any deep extent (Alexander; 2004). Modernism has been called into question as the "soulless container architecture" (Leach; 1997) so, the disappointment with functionalism at the end of the twentieth century turned the form-function relation to the relation between form and meaning, furthermore, meaning is not something apart from function, but is itself a most important aspect of function. The return of meaning presents a topophilic (Bachelard; 1994) and biophilic (Almusaed; 2011) reconciliation of people with the built and natural environment, a re-discovery of latent meanings in the genius loci (Norberg-Schulz; 1979). Architecture means to visualize the genius loci, and the task of architect is to create meaningful places, whereby he helps man to dwell. The rapid spread of the amenities and conveniences of modem life created a uniform but a less personally and socially meaningful built environment. In turn, architectural symbolism can act as an onto logical context and a field for exploring the dialectics of relationship between people and built environment (Akkach; 2005). If architecture goes beyond utilitarian needs, as Le Corbusier asserts, then religious architecture certainly applies. Here the ordinary place and space is presented and represented into "extraordinary" meaningful poetry of relationship between people and built formas well as its surrounding environment. Symbolism and/as meaning is the departure point for a phenomenological approach of Mosque Design as the scrutinized subject and object of this paper. "Reading" the poetics of architecture - form, space and structure - as well as "writing" architecture is the methodological framework for catalyzing a 
theoretical approach on Mosque - Urban Mosque - as a representative built form through the lenses of implicated disciplines; religion / Islamic studies, philosophy/epistemology, psychology/Gestalt psychology, cultural studies, linguistics/semiotics as well as poetry. Furthermore, Mosque is the appropriate and ultimate focal point to look at architectural is sues from the perspective of faith and vice versa.

Taking a theoretical approach towards Mosque as a built form is as challenging as taking a design approach, yet this paper takes both challenges as well as opportunities within the context of current societal and technological developments.

\subsection{A short etymological, ontological and historical account of Mosque as institution and built form}

The root of Arabic word for sanctuary, Masjid is sejede, which means to prostrate, in fact prostration is the highest act of ritual prayer in Islam, salāt. Hence, prayer (salāt) is the raison d'être of ontological Mosque.

The place and space which gathers the Muslims for congregational prayer traditionally is referred as jāmi, from Arabic, jámī; jamā, jammeā = congregation, gathering, union.

Before being a space, a Mosque is a place, and this place according to Islamic teachings is the earth itself, the whole earth as the Mosque. This can be clearly as serted from the Prophetic sayings, "Wherever you pray, that place is a mosque" and, "I have been given the whole earth as a mosque (place for prayer)" or "the whole earth has been made a mosque for us". Yet, these Prophetic sayings raise questions about how and why an identifiable Mosque architecture emerged and developed. In its formal and compositional characteristics, the typical Mosque remains an intriguing phenomenon that is ance simple and complex. It is simple in that a number of recurrent elements can be traced in various compositions throughout the premodern and modern periods, revealing a consistent identity. Yet it is complex in that the model perpetuated in many elaborate forms has little to do with the function it serves. Hence, the relation of form and function of the Mosque remains a perplexing and challenging task in architecturaldesign. Moreover, the Prophet's Mosque in Medina as the generic and precedent of all Mosques is so "simple" and "profaned" that seemed hard for the historiography, especially western historians and theoreticians to grasp it as a sacred building from the viewpoint of western epistemology that has clearly polarized the "sacred" and the "profane".

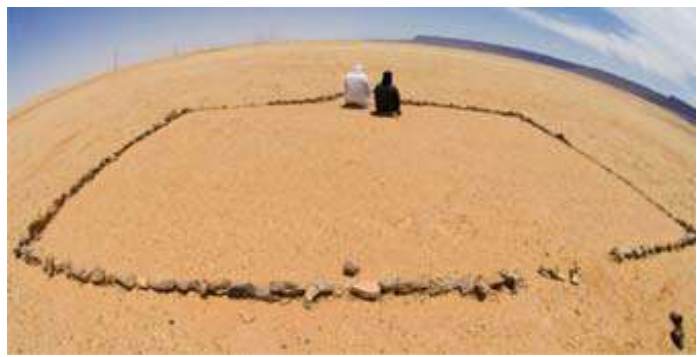

Fig. 1. The whole earth as prayer place - Mosque. The designation of a sacred zone by setting out demarcating boundaries can be traced in some premodern Islamic references. Many early places for prayer were said to have merely lines drawn in the sand. (Akkach; 2005).

Source and Photo Credit (C): Corbis.

\subsection{The Prophet's Mosque in Medina as the Eternal and Generic Mosque}

The very first piece of Mus lim Architecture was the Mosque that the Prophet Muhammad (p.b.u.h)built himself at Medina in 622 AD. It was a square enclosure surrounded by walls of brick and stone. This simple structure had the portion of the roof under which the Prophet led the prayer made of palm sticks and mud, and it was supported on columns made from palm trunks. Furthermore, this simple structure served as a religious, social, political and educative center.

In this line, the function of the Mosque as an institution is well set from the two main Islamic sources; the Holy Quran and the prophetic sayings, the Hadith which constitutes the Prophetic tradition, the Sunnah. Yet, the question how the Mosque as institution - function it serves - is related to the 
representation of this function - the form - remains quite ambiguous and frequently in the domain of conjecture. Taking this point as challenge and opportunity, this paper presents a methodological framework through theorization of our design proposal for the Central Mosque of Prishtina as case study, even though, the paper is not exclusively framed into this case study, as it takes also an inclusive and holistic view of the issue.
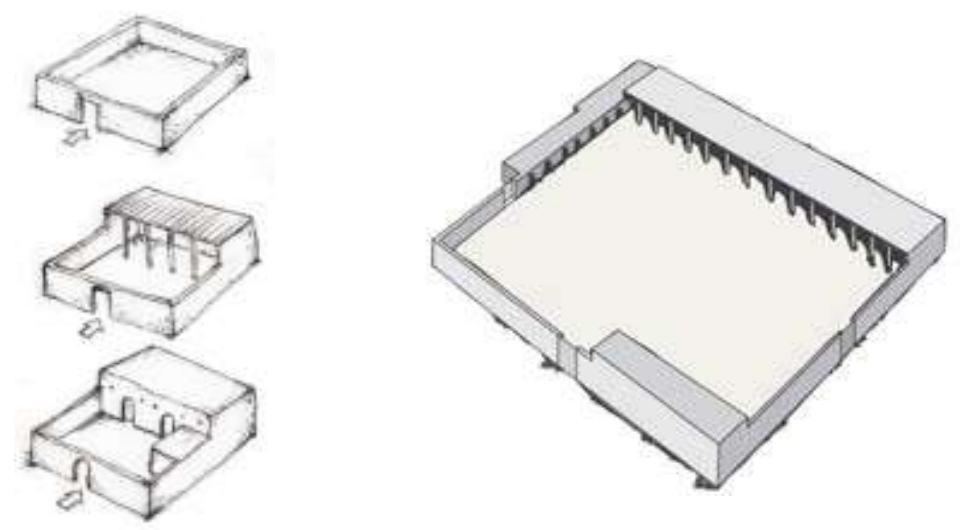

Fig. 2. (Right) the House and Mosque of the Prophet Muhammad p.b.u.h. at Medina: The Islamic prototype of both religious and residential architecture. (Left) regional architecture of House types of Arabic Peninsula, specifically from city of Medina.

Source: Author's drawings after Prochazka; 1986

\section{Phenomenology Of Architecture As An Ontological Context For Approaching Mosque Design}

Phenomenology implemented in architectural design relies in the manipulation of structures, elements and sequences of space, materials, light and shadow to create memorable encounter through an impact on the human senses. Phenomenological approach to architecture proclaims that the senses be stimulated by the design not merely the visual stimulus but also tactile and feelings. This is clearly asserted by Peter Zumthor; materials in architecture can be made to shine and vibrate. In the phenomenology of architecture, the Euclidian geometric space is transcended into a space of meanings as "forces" to be felt. In this sense geometry has the power to articulate spatial relations and materiality which in turn can reflect how buildings embody and encode social, cultural and material knowledge and information, which embodiments can be then decoded by the particular society/user (Rapoport; 1990).

Fig. 3. The atmosphere of spave,

Source: Author's photo courtesy

Religious buildings traditionally represent a "container" of encoded multivocal meanings, which meanings are mostly embedded into symbolic forms of architecture itself. Mosque architecture in this sense is a phenomenological container of meanings embedded, represented and decoded by the 
particular users, and at this point this provides an interesting ontological context to approach the contemporary Mosque design.

Being itself prescriptive and normative in behavior not in form, Islam provides no ready-made recipes to establish design standards for Mosque as a built form, in this line Islamic architecture, traditionally derives its meaning from the usage rather than the from imposing a meaning. Here the question that rises is how then distinctive features and typologies on Mosque design appeared and crystallized? Does Mosque represent an autopoietic system (Schumacher; 2011) "appeared" out of a solipsistic epistemology? A practical answer would be that the Mosque architecture draws upon sources of inspiration from the legacies of the past, the promise of the present, and the inspired visions of the talented individuals - architects, artists and artisans. Yet the question of phenomenology is not fully constrained within material boundaries. Symbolic meanings have played a deep role in shaping the visual language of Mosque as a representative, legible built form. In one hand they have maintained the legacy with the past but in the other hand have "limited" the design creativity through a stress of Muslims to become more "normative" which led to the so-called "pan-Islamic" style.

\subsection{Symbolism of architecture as a mean of articulating meaning}

Symbolism is a current topic in many disciplines; its discourse is multifaceted. Psychologists, anthropologists, cultural theorists, social scientists, historians of religion, historians of art and architecture, philosophers and architectural theorists, have all developed viable dimensions of the discourse. The wide interest in the topic in the humanities and social science disciplines points to its significance in understanding humankind and its situations in the world. Man cannot gain a foothold through scientific understanding alone. He needs symbols, that is, works of art which "represent lifesituations".

One has also to distinguish between signs and symbols. Historically there have been different theorizations and implications in defining symbols.

Signs are supposed to be univocal, that is, to have a one-to-one correspondence to what they stand for because they are related to those things fairly directly. Symbols, on the other hand, are supposed to be multivocal, that is, they have a one-to-many correspondence and are hence susceptible to many meanings. Hence, symbolization manifests itself through experienced meanings "translated" into another medium, while that medium continues to remain itself (Eliade; 1968). Symbols and signs are commonly understood and used as means of communication; in architecture they represent the nonverbal communication between the built form and the user.

In Islamic architecture, symbolism mediated historically and theoretically between the polarity and dichotomy of meaning-oriented and beauty/pleasure-oriented, especially in the case of ornament. Moreover there is an inconsistency how the terms symbol and sign were used in the pre-modern Arabic literature and how it is used in the contemporary Islamic architectural discourse.

The Arabic terms $\bar{a} y a, r a m z$, ishāra, 'ibara, mithāl, and dalīl are all used to denote various shades of both 'sign' and 'symbol.' All are used in the Quran; however, the term āya is the most nuanced and frequently used. $\overline{A y a}$ literally means "mark" or "sign" but is most commonly used to refer to a Quranic "verse." The most potent meaning of the term, however, is "symbol" as in the widely quoted verse: "We shall show them our symbols (āyāt) on the horizons and within themselves until it will be manifest unto them that it is the Truth" (Quran 41:53).

$\overline{A y} a$ also means warning, example, lesson, indication, miracle, wonder, marvel or prodigy. All these meanings are contextualized in the Quran:

"If all trees in the earth were pens, and if the sea eked out by seven seas more were ink, the words of God could not be written out to the end." (Quran 31:27)

"Do you not see how God cites a symbol: a good word as a good tree, its root set firm and its branches in heaven." (Quran 14:24)

"And of his symbols is this: he created you of dust, and behold you human beings, ranging widely!" (Quran 30:20)

From the perspective of philosophia perennis, forming an integral part of the sensible world, architectural forms are considered as eminently appropriate to act as symbols. In the pre-modern Islam, cosmological meaning and interpretation of architectural components and forms was stressed especially from the Sufism, yet, Sufism traditionally had tenuous relationship with mainstream Is lam, which makes 
it hard and ambiguous to interpret or implement those ideas in the contemporary context of architectural discourse.

Taking symbolism as a means to articulate meaning into architectural form and space, we will elaborate this approach in our proposal for the Design of Central Mosque of Prishtina.

\subsection{Poetic meaning of architecture}

Holl et al (2006) asserts that if architecture can be said to have a poetic meaning we must recognize that what it says is not independent of what it is. Perhaps the most comprehensive work concerning the poetics of space applying the method of phenomenology to architecture is from French philosopher Gaston Bachelard, The Poetics of Space. A highly philosophical approach but tangible on lived experience of architecture.

The relation of architecture with poetics is also as serted by Le Corbusier: Architecture only exists when there is a poetic emotion. In this sense poetics, symbolism and meaning represent the tangible and transcendent features of the phenomenology of architecture.

Representation of "sacred" as light and space and light in space was the core theme in Gothic architecture. Also space as an immaterial idea and its atmospheric qualities were the poetic articulation in the Gothic "drama". In this sense Le Corbusier asserted that: the cathedral is not a plastic work/it is a drama / a fight against the force of gravity, which is a sensation of a sentimental nature. Hence, symbolism and poetics are part of the phenomenological language through which architecture speaks, and as such are the main themes in elaboration of this paper.

\section{Urban And Architectural Conception - Harmonizing And Reconciling The "Tension" Between Two Fabrics}

Buildings are more than morphological entities as they produce interventions and situations. Urban Mosque is a building that operates under unique existing site constraints (Kahera et. al, 2009); as such it creates a "tension" in the urban fabric.

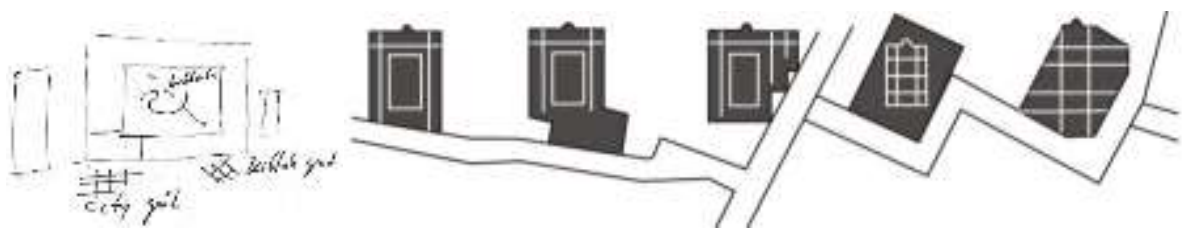

Fig. 4. (Left) sketch depicting city grid and Mosque grid in the proposed site. (Right) architectural solutions for "reconciling" the city grid with kiblah grid

Source: Author's drawings after Prochazka; 1986

Is lamic prayer requires no tangible object to be performed. As prescribed by the Prophet p.b.u.h.prayer in Islam is an act of worship performed toward the liturgical center, the Ka'ba, which - except the Holy Mosque in Mecca - lies beyond boundaries of all Mosques. In this sense Islamic prayer does not represent any pictorial act. It is the directionality which orients and unifies the believers in the ritual prayer, which conditions the orientation of the prayer space towards Ka'ba, in the same time revealing an architecturalcondition. The orientation as a preset makes the Urban Mosque a unique building within the urban fabric, with its autonomous grid imposed to the city fabric. 


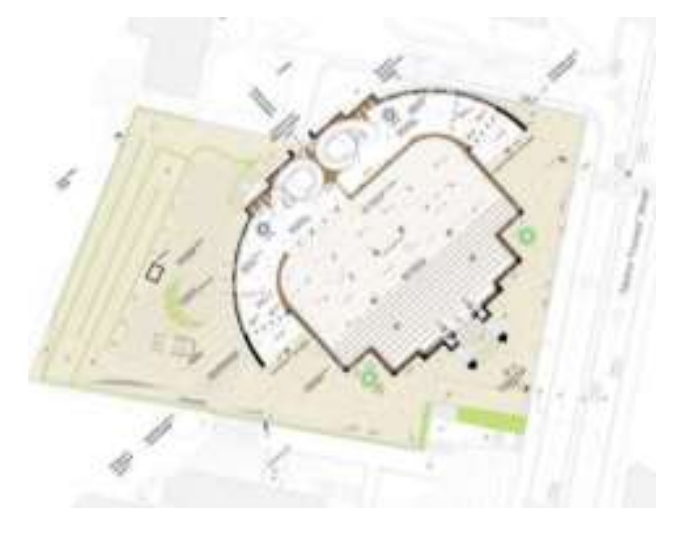

Fig. 5. Mosque ground floor showing urban integration and contextualization through communication theme.

\section{Source: Author's drawing}

For our proposal of Central Mosque in Prishtina the directionality is taken as a theme and regenerative urban concept. In one hand it clearly depicts the Mosque as an "autonomous" and distinctive built form, in the other hand integrates it within urban fabric through two passage-ways, one running in the kiblah axis and the other transversally crossing it. The main entry situated in the kiblah axis as well as side entries de-constructs the normal entry situation, placed in the kiblah direction but leading opposite to it (see Fig. 5 and 9). This provides an "organic" approach of contextualization which re-defines traditional spatial schemata.

The layout of contextualization is further emphasized with spatial/ volumetric configuration of the Mosque as a corpus that tends for harmony in the urban context.

\subsection{Spatial tendencies of the Islamic prayer as symbolic embodiments in Mosque spatial /volumetric configuration}

Is lamic ritual prayer consists of prescribed set of gestures / actions and recitations, performed the same way, whether in individual prayer or in congregation, while standing at a fixed point in space. It involves a series of bodily postures rhythmically repeated in one place with no processional ritual. The spatial tendencies of Is lamic prayer go from vertical to stationary to horizontal, and at this point they reveal an interesting symbolic action to be embodied in our generative idea for conceptualizing spatially our proposal for the Design of Central Mosque of Prishtina.

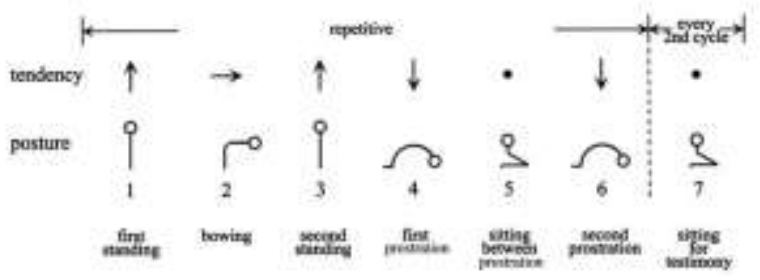

Fig. 6. The bodily postures and as sociated spatial tendencies of the Islamic prayer.

Source: Akkach; 2005

There are four principal postures: standing (qiyām), bowing (rukū), sitting or resting (julüs), and prostrating $(s u j \bar{u} d)$. The movements associated with these bodily postures reveal four tendencies: upward, associated with the standing posture; horizontal, associated with the bowing posture; downward, associated with the prostrating posture; and stillness, as sociated with the resting posture. 
The four characteristic postures in ritual prayer were taken as numbers and tendencies for articulating the volume of the Mosque in four cascaded coherent volumes, symbolizing the fo ur bodily postures in ritual prayer. As the Mosque is a place and space that hosts both genders equally into ritual prayer, the four cascaded volumes are mirrored from the symmetry ax which represents the axis mundi of liturgical center, the Ka'ba.

The cascading down of the volumes in two sides of the kiblah axis is a gesture of prostration, humility and submission as an essential element of belief, as well as an "organic" contextualization and harmonization into urban fabric.

\subsection{Divine Proportions - Golden ratio and Root rectangles as embodied containers of bodily postures of Islamic prayer}

From Vitruvius, da Vinci's Vitruvian Man, to Le Corbusier's Le Modulor, the concern with anthropometric scale of human proportions was evident. Moreover proportions were used as canonic rules of cosmic order in western and Islamic pre-modern architecture, sacred and profane.

Determining the four interconnected volumes, symbolizing the four characteristic bodily postures and their tendencies in ritual prayer, we have strengthen the theme further by using "Divine" Proportions Golden ratio and Root rectangles - to proportion these volumes in both sides of symmetry axis. The central volume is proportioned with golden ratio, while the side volumes with root-two and root-four rectangle, reflected in bilateral symmetry.

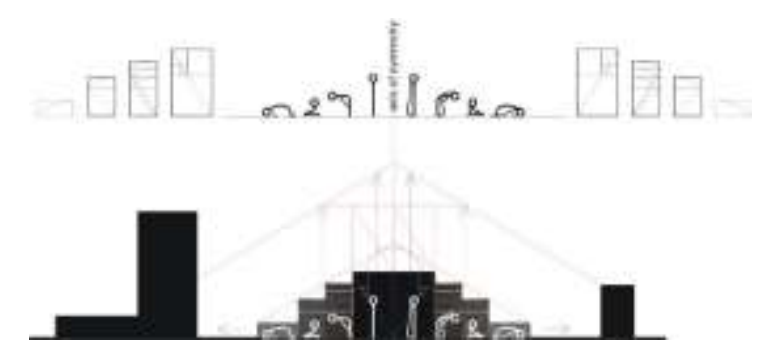

Fig. 7. Conceptualizing and symbolically embedding bodily postures of the Is lamic prayer in the corpus of the Mosque as a representative built form, symbolizing submission through prostration.

\section{Source: Author's schemes}

Geometry here is used as the medium and representation of a generative concept. Moreover, geometry captures not just abstract patterns but also the visual framework of these patterns, turning abstract rules into representations. Crossing the divide between the abstract and the visible, geometrical systems represent our knowledge as visual entities and as abstract conceptual structures.

\subsection{Curvature of Mosque volumes as store of information}

Inward curved walls of Mosque exteriorities are conceived to promote the centripetal character of the Mosque in one hand and in the other hand to symbolize a melting down of the Mosque into the courtyard. According to Layton (2006) shape is the means of reconstructing history and a means by which past actions are stored, in this line a building should be a maximum memory store. Large amount of memory can be stored in a particular type of as ymmetry: the curvature extrema of a shape. Moreover, Layton as serts that memory is erased by symmetries and stored in asymmetries, which theory puts into doubt and redefinition the whole Euclidian geometry. Further, memory and meaning are interconnected and built form is their container. Retrieving and decoding information/ memory has a particular importance in phenomenology of architecture, which sees aging of a building and its pathos as information and memory stored into the material and form. Peter Zumthor asserts this clearly: I am convinced that a good building must be capable of absorbing the traces of human life and thus of taking on a specific richness. Naturally, in this context I think of the patina of age on materials, of innumerable small scratches on surfaces, of varnish that has grown dull and brittle, and of edges polished by use. 
The inward curvature of Mosque creates a profile and contour that store information and elicit meaning to the user of a known metal image that is a Mosque encoded by their intuition.

\subsection{Profile and contour - mnemonic features of Mosque as a legible built form}

The Kiblah wall with its cascaded volumes ending with topological domes constructs a legible mental image of the Mosque captured as a silhouette of traditional Mosque. Profile and contour of the articulated volumes act as mnemonic features of Mosque as a legible built form. Le Corbusier asserts that profile and contour are the touchstone of the Architect.

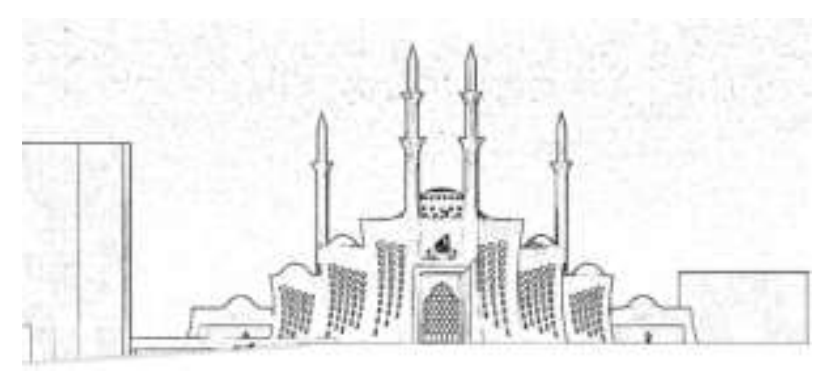

Fig. 8. Profile and contour of the Mosque depicted through a legible silhouette of re-constructed traditional grammar of classical Mosque architecture.

Source: Author's rendering

Eliciting associations, encoding information and known images of traditional Mosques, the kiblah wall acts as a container where the user would "unconsciously" and intuitively decode the cues of a built form that is known to him. Moreover, these cues are constructed in many layers in the exteriorities of the Mosque in order to provide redundancy in orientation, and identifiable schemata of reading spatial elements and features.

\subsection{Articulation of exteriorities as redundant cues}

In an unfamiliar environment nothing is more meaningful than a familiar image, cues that orient you in perceiving, conceiving and using the space. These familiar images communicate nonverbally with the particular user through, what Lynch (1960) has called as "imageability". In reality "imageability" is the environment quality which protects man against getting lost, which means that shape, color or arrangement facilitates the making of vividly identified, powerfully structured, highly useful mental images of the environment (Norberg-Schulz; 1979).

Emphasizing the kiblah axis as well as giving a clear indication and a gestural sign of main entry, the Gate in our proposal represents a mediator between the inner and outer space. It is a cue of orientation which sequences the elements of inner space. The Gate is also the starting point of the water theme and the unifying frame for the "sacred and the "profane" as it leads you to the prayer space and it's adjacent amenities as well as a number of other functions (library, recreation room, child daycare center, etc).

In traditional Mosque architecture, the schemata of orientation and legibility are no doubt articulated almost worldwide with the vertical structure, the minaret. Etymologically, the word minaret derives from Arabic, manáre, originally meaning a lighthouse or signaling tower. The first Mosques, including the very first Mosque the Prophet p.b.u.h. built, did not have a minaret. The call for prayer - Azan initially was performed from rooftops of the Mosques. With the spread of cities, the Azan could not be hared from those living in the distant periphery, in this sense the minaret appeared as a tall architectural structure where Azan could be called and hared in greater distance. The first documented minaret was built abound 665-666 AD in Basra of Iraq (Prochazka; 1986), 44 years after the first Mosque in Medina was built. 


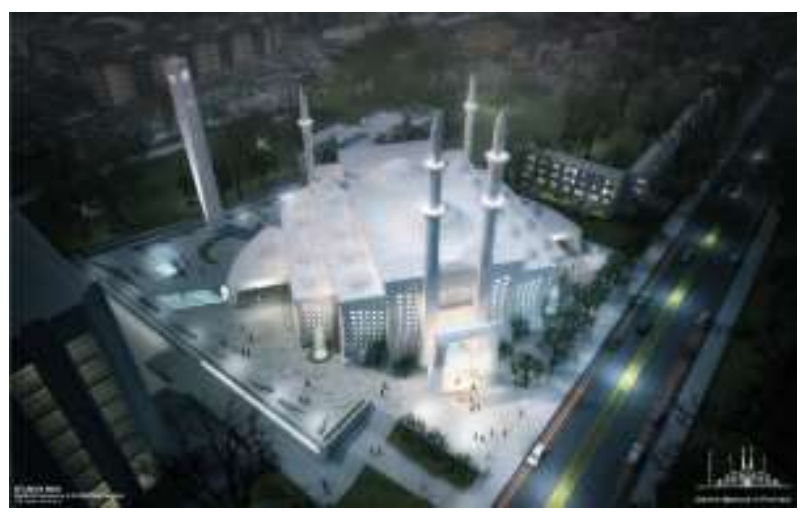

Fig. 9. Night rendering of the Mosque showing the articulation of external themes as redundant cues.

Source: Author's photo/rendering courtesy

In our proposal, minarets represent symbolic and structural tectonics in articulation of the architectural body. They determine and emphasize the regulation lines of symmetry axis, the entry gate, balance the kiblah wall and create coherent volumes. Moreover minarets fulfill the "imageability" of the Urban Mosque within the urban scheme as elements of orientation and identification.

To complete the schemata of "imageability" of an Urban Mosque which supposed to take the role of the Central Mosque, we have proposed another vertical structure, reminiscence to the traditional city core, a tower clock, which is symbolic as it represents time connected with temporality of prayer and in the same time it is a landmark identifying and distinguishing the new Central Mosque. Moreover, its position and form, reconciles the two grids, the urban grid and the kiblah grid, as it twist up from one to the other.

Continuing the theme of the schemata of orientation, Mosque courtyard is conceived as a pattern of directional filed. The motif of openings in the walls of the Mosque is continued down in the courtyard as pattern of ground lighting leading and orienting people to access points, hence, creating a directional field.

\subsection{Articulation as ornament - openings as motif}

The meeting of interior and exterior "forces" and "energies" in a built form is expressed in the wall, and in particular in the openings which connect the two "domains". As a process of making, architecture is articulated in its whole domain.

Articulation determines how a building stands and rises, and how it receives light. The word "stand" denotes its relationship to earth, and "rise" its relationship to the sky. Verticalism and religious aspiration have in fact always gone together. In general, openings serve to concretize different insideoutside relationships. "Holes" in a massive wall give emphasis to enclosure and interiority. Openings also receive and transmit light, and are therefore main determinants of architectural character. Openings can become motifs.

Architects look to their past not as much for models of form - though they do so - as for validation of their current ideas. It is not that new ideas cannot be developed through the thought of design but that such values must be able to be reconciled with those that have emerged from the great buildings of the past. Redefining the openings of the traditional Mosque is in the same time a validation of our idea as well as reconciliation with the strong character of the traditional Mosques in Kos ov o and in the region around.

Inspired by traditional wooden lattice work of windows, as well as the elegance of Is lamic calligraphy, we have re-interpreted and composed the openings for the Central Mosque as motifs which are to be read as autogenic structural ornamentation (Douglis; 2009). Here ornament is embedded into structure not as an appliqué mere decoration, it flows naturally as a motif of light ascending down. Moreover it 
defines the unique character of the Central Mosque within the urban context as an autonomous, autopoietic, yet legible structure.

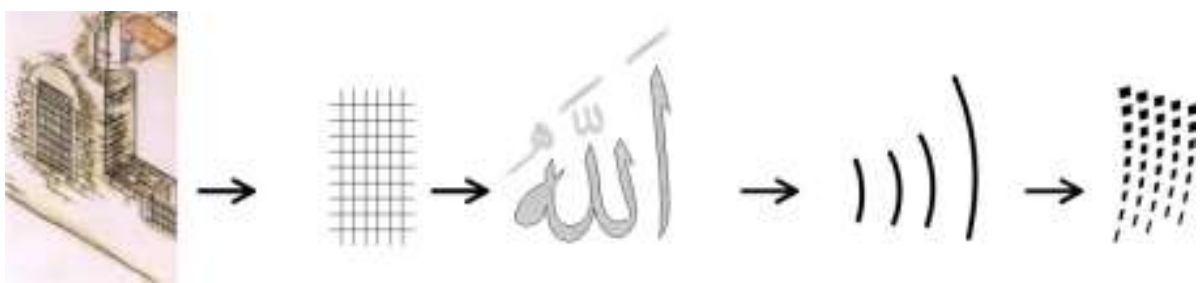

Fig. 10. Reinterpretation of openings in the Mosque inspired from tradition and Arabic calligraphy.

Source: Author's scheme

The articulation of openings as motifs goes hand in hand with the preservation and imposition of the "mass" as visual weight, reminiscence to the traditional houses in Western Kosovo, the Kulla (Tower House), which structures originally are characterized with small openings (fringji) pierced into the massive stone walls.

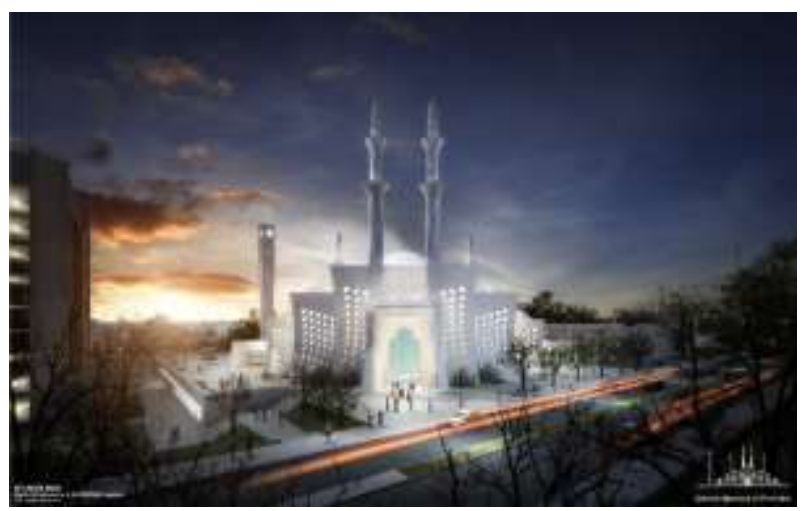

Fig. 11. Night rendering of the Mosque, showing the kiblah wall with the openings articulated as motif of spaces and light.

Source: Author's photo /rendering courtesy

The openings represent a progressive sequence from small to large, from bottom-up, having the potential to signify or imply movement. This movements which creates the dynamics of architectural form and mass, creates verticaltendencies of ascending and descending, in the same time creating mass at the bottom of the building and "lightness" at the upper portion. The dynamics of architectural form are further intensified by tilting the openings into an angel, which creates tension and in the same time achieving a compositional harmony where parts are perceived in the whole.

\subsection{9 openings symbolizing 99 Names of Allah (Asmāal Husnāa)}

The abstraction of calligraphy into openings is further embedded into symbolic interpretation of 99 Names of Allah (Asmā-ul Husnā) through 99 openings in each side of the symmetry axis of the Kiblah façade. Here the number 99 is a mnemonic feature that bears the meaning symbolically while the explicit engraving of the unique name of God - All-llah - decodes this information to the user.

\section{Light Theme - From Metaphysics To Atmospheric Qualities}

All things are given their name and place, including buildings, by sunlight. Light "shapes" and "tames" forms, masses, surfaces and reveals their sensual and tactile expressions. For Le Corb usier: 
The elements of architecture are light and shade, walls and space. Light ensouls buildings (Day; 2004).

Light and shadow animate the natural and built forms. The phenomenon of shadow has always intrigued the human mind. The shadow's curious relationship to the object it maps has often formed the object of philosophical reflections (Akkach; 2005).

"Have you not seen how your Lord has spread the shadow (zill)? And had he willed, he could have made it still" (Quran 25:45).

Light is not only the most general natural phenomenon, but also the less constant. Light conditions change from morning to evening, and during the night darkness fills the world, as light does during the day. Light, thus, is intimately connected with the temporal rhythms of nature which form a fifth dimension of understanding.

\subsection{From light to delight - the theatrical effects of architecture}

Light as presence, darkness as absence have been used constantly in religious architecture to evoke the "sacred", by creating metaphysical theatrical effects. As the visible most "intangible" domain, light is the source of truth ascended in earth to reveal the real human drama. The spatio-temporal effects of natural light have been used in many levels in our proposal for the Design of Central Mosque of Prishtina. First, the deep openings, piercing the two shells of the wall, create spaces filled with light, which articulate the interior with different levels of shades and brakes the sequences of space into patterns of visual perception. Second, light is taken as a floating theme from many directions, including the upper boundary of the space, entering from the oculi of domes and flowing down by creating a theatrical effect in a drama of light and shades in a multi-dimensional animated space. Furthermore, the light theme is emphasized with visual connectivity in-between floors by using "floating" floors, where slabs touch the lateral walls only through "bridges" which we have called the "Quran bridges" as they are articulated as spaces where bookshelves and sitting places for reading are carved into the rammed earth massive wall. Here light is the mediator of different vertical levels by creating the unity of prayer spaces, physically and visually connected. Yet, the light theme is articulated in hierarchies and sequences in order to break up the large space. By preserving the traditional central space under the dome, the main dome is the highest point with largest number of openings/ oculi bringing the highest amount of light, cascading down with volumes the light theme gets to the very human scale of spatial proportion.

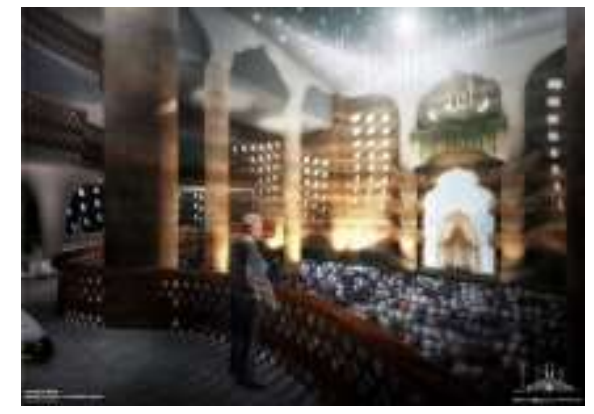

Fig. 12. Interior rendering showing the whole domain of interior themes articulated and narrated in light, rammed earth and kiblah axis / wall. Source: Author's photo/rendering courtesy

Light theme here represents the phenomenological perspective view of performance as well as a theoretical, aesthetic and communicative perspective on performance.

\section{Interiorities As Narrative Themes}

Elaborating themes that do elicit meanings to the user, interiorities of our proposal were taken as narrative themes of orientation and symbolic interpretation of Mosque fixed and semi fixed-features. 
The Mihrab (niche) and Minbar (pulpit) as "furniture" of the Mosque, in our case are composed as a multifaceted narrative theme. First of all they represent the act of orientation, emphasizing the kiblah wall and kiblah axis; positioned in the axis of symmetry they represent the climax of sequences in interior spaces. With two giant columns wrapped on rammed earth to create visual mass, the kiblah axes is further emphasized with the huge glazed opening / window, which provides the highest concentration of light in the Mosque, in front of it, the semi-perforated and semi-translucent foil-like Mihrab, is situated.

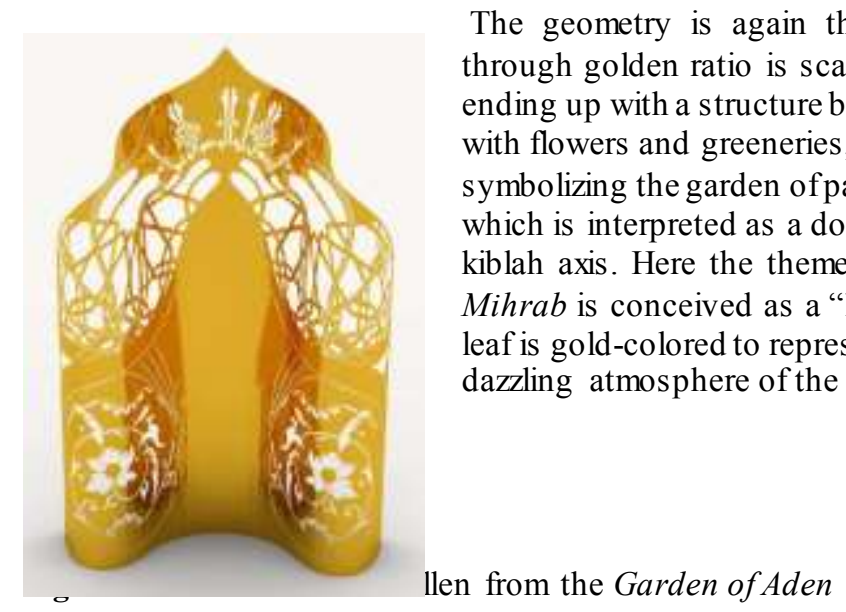

Source: Author's photo /rendering courtesy

The glazed surface behind Mihrab is conceived as a river cascading down, where water flows down the lattices, creating the cascade-like effect and the sunlight reflect the moving water into the interior space, animating it an narrating the theme of water, light, earth and greenery, where air is the mediator filling the atmosphere and holding the phenomenology.

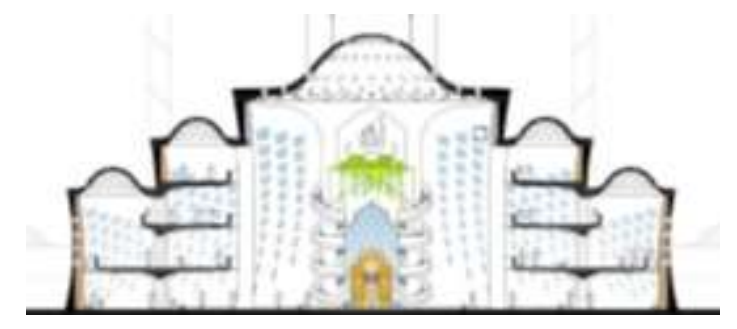

Fig. 14. Transversal section showing the articulation of Kiblah wall as a narrative theme

Source: Author's drawing

The highest point of kiblah wall in the kiblah axis ends with an engraved calligraphy of the unique name of God in Islam - Allah - which marks and decodes the 99 openings in each side of the kiblah wall, standing for 99 names of God. Surrounded by two crescent moons, they symbolize the light into darkness, a clear sign of the true path.

The interiorities of the Mosque represent a drama, where poetry is narrated as a set of themes embedded into autogenic space and structures. 


\section{Water Theme In-Between Hierophany And Sensual Performance}

The phenomenon of water has universal and particular meaning to all heavenly religions. For Elaide (1968), in whatever religious complex we find them, the waters invariably retain their function; they disintegrate, abolish forms, "wash away sins"; they are at once purifying and regenerating. Water as life-giving and regenerating is clearly depicted in the Holy Quran:

"And of his symbols (āyāt) is this: he shows you the lightning for a fear and for a hope, and sends down water from the sky, and thereby quickens the earth after her death. Herein indeed are symbols (āyāt) for folk who understand." (Quran 30:24)

Waterscape is a very important theme in the Islamic architecture in general and in Mosque architecture in particular. Water is very important to the Mosque due to the ritual wash - ablution - that Muslims must perform before prayer. So, it is a direct implication to the concept of purity in Islamic teachings. In Islam, water is seen as primordial, life-giving, sustaining, and purifying.

"...We made every living thing of water." (Quran 21:30)

"... For Allah loves those who turn to Him constantly and He loves those who keep themselves pure and clean."

(Quran 2:222)

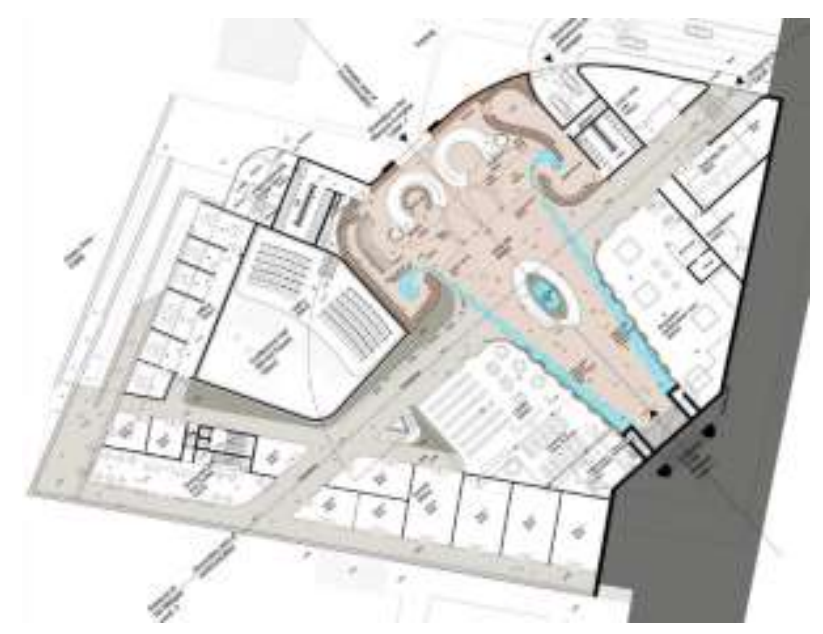

Fig. 15. Level -1 of Mosque complex, showing water theme as a narrative and directional "field" of orientation.

Source: Author's drawing

Water is used in Islamic architecture for several basic reasons. First, it is used practically to provide cooling in hot, dry climates. Second, it is used aesthetically to emphasize visual axes, reflect the surrounding environment, and visually multiply the adjacent architecture and its decorative detailing. Third, it is used symbolically to represent the life-giving, sustaining, and purifying aspects of water mentioned in the Quran, like the ablution fountains found traditionally in the central courts of Mosques, where the believers would perform the ritual wash five times a day.

The symbolic manifestation of the "sacred" is termed by Eliade (1968) as hierophany. In this line water used in Mosque architecture is a multivocal manifestation of Islamic teachings for purity and also a symbolic representation of the gardens of paradise under which rivers flow. In reality it is almost impossible to make a clear distinction of water theme used as symbolic hierophany or as performative 
theme (i.e for cooling effects). As LaVine (2001, p.6) asserts; there are no entities in this world that can simply be split into issues of measurable performance and those of interpreted symbolic meaning because our own experience of the world from which our buildings arise cannot be divided in this way.

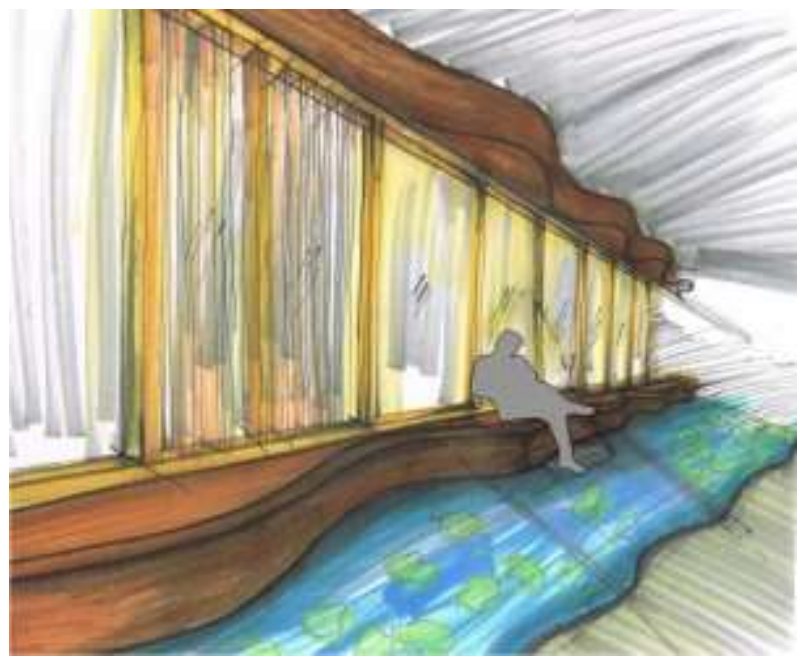

Fig. 16. Hand-rendering depicting water channel passing aside rammed-earth wall of the Library.

Source: Author's drawing

Taking into account the above elaboration of water theme we have used it in a multivocal way in our proposal for the design of Central Mosque of Prishtina. First of all, water here is taken as a theme of orientation, in one hand emphasizing the kiblah axis and in the other hand leading you the way to ablution zone as a magnetism of the target (Arnheim; 1977). This is the way toward a double purity, the physical purity of water in the ritual wash and then the spiritual purity in the ritual prayer. "Where is the ablution zone?" it's an odd question. "Follow the water stream" is the answer. Symbolically the starting points of the water theme are the two massive, white marble blocks in each side of the main entrance to the Mosque complex. Their white color symbolizes the purity and their hardness is a parable of what God Almighty has revealed in the Holy Quran:

"Then your hearts became hardened after that, being like stones or even harder. For indeed, there are stones from which rivers burst forth, and there are some of them that split open and water comes out, and there are some of them that fall down for fear of Allah. And Allah is not unaware of what you do". (Quran 2:74)

From the two marble blocks, water flows down in two sides of the passageway as two channels, the left one leading to the male ablution zone and the right one leading to female ablution zone. Here water creates a gender dichotomy within the spatial unity by providing cues for spatial orientation in the sequencing of space. The walls aside the water channels are elaborated as "living" walls, revealing the materiality of the interiorities of the Mosque - rammed earth - which provide a livable place and space, a place where you can sit in the niches of mas sive rammed earth wall accessed through the glass bridges. Here the phenomenology of architecture reveals itself in its full range, from hierophany to tactility and sensual performance, as water, earth and cooled air provides the atmosphere of a sociopetal space (Lawson; 2001), a place that generates social encounters. The energies of encounter are stressed as well in the creation of a "node" where two passageways intersect. This node is both communication and a symbolic act of purity, as it represents the act of ablution washing out the sins. In this way, the node is an elliptic ramp connecting two levels, while the void is a sculptural elliptic cone which we have named the "Pillar of Prayer" standing for one of the five mandatory conditions/pillars of Islam. This cone is materialized in two shades, the white marble which covers most of it and the black marble melted at the bottom of it. Water gushes from the top of it symbolizing ablution, while the white marble symbolizes the wash away of sins - black marble - from ablution waters. Water theme is both a spatial narrative and a system of communicating meaning, where symbolism interacts with the performative values. 


\section{Sensual Tactility - Earth As A Phenomenological And Performative Material}

Earth represents a primordial "ordinary" material with extraordinary features in all ancient cultures, and it was used not only for building homes, but also for religious buildings. As a traditional material it contains the social, cultural and material traces of life. It is a material which provokes humility and elicits tactile experience, creating memorable encounters.

An Italian proverb asserts that "There is nothing in life so ordinary that it cannot be made extraordinary." The first step in designing something extraordinary is to define the elements that make it ordinary. Thoughtful manipulation of the ordinary state of form is a contributing factor in bringing forth new images. Earth construction techniques have been known for over 9000 years, and ev en today, one third of the human population resides in earthen houses. Earth when used as a building material is often given different names. Referred to in scientific terms as loam, it is a mixture of clay, slit, sand, and occasionally stones. When compacted within a framework, it is called "rammed earth". Loam is able to absorb and desorbs humidity faster and to a greater extend than any other building material, enabling it to balance indoor climate. Like all heavy materials, loam stores heat. The preparation, transport and handling of loam on site requires only ca. $1 \%$ of the energy needed for the production, transport and handling of baked bricks or reinforced concrete. Loam, then, produces virtually no environmental pollution. It is often maintained that earth walls help to clean polluted indoor air. Provided the building process is supervised by an experienced individual, earth construction techniques can usually be executed by non-professionals. As asserted by the mystic poet Rumi: "Earth turns to gold in the hands of the wise."

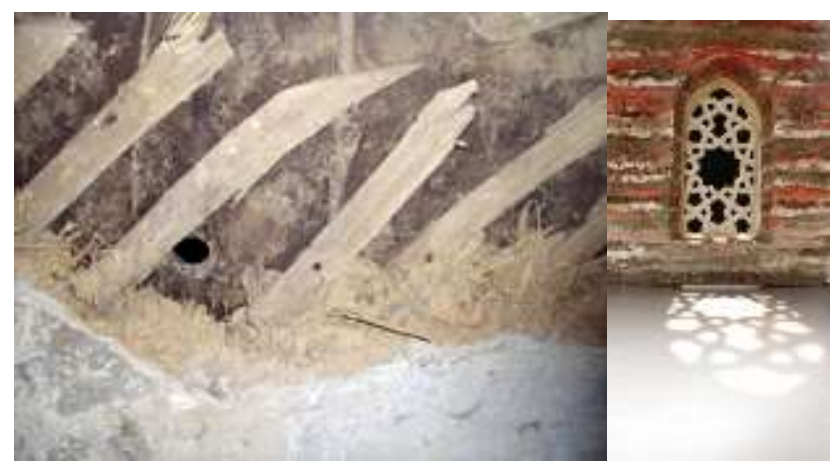

Fig. 17. (Left) earth and wooden lattices used as finishing material in vernacular architecture in Kosovo. (Right) study model of rammed earth wall and window as an atmospheric space. Source: Author's photo courtesy

Yet, nowadays, living in the "whitewash" environment people have often prejudices against earth as a building material. And again Rumi wrote:" We live on earth yet so ignorant of earth and all the treasures it holds."

\subsection{Rammed earth as tactile autogenic ornamentation}

In contrast to exteriorities with white insulated concrete as the ultimate material and expression, the interiorities of the Mosque are constructed as inner shell in rammed earth technique. Considering the above mentioned extraordinary features of the earth as a natural and ecological material, we will further explore more attributes.

Besides its outstanding thermal, ecological and other physical properties, earth has a strong meaning in Islam, as the "raw" material in the creation of first human being, Prophet Adam p.b.u.h. Much more, earth is the abode in the graves, while from it is the resurrection, God Almighty asserts this clearly in the following verse:

"From the earth We have created you, and to it We shall return you, and from it We shall raise you again" (Quran 20:55). 
Further more (clean) earth is used as material to perform ablution - tayammum - when one can find no water, by placing his hands in the (wall) surface or the ground and then rubbing his face and his hands. It is transmitted that the Prophet p.b.u.h. said:

"The earth has been made for me (and for my followers) a place for praying and a thing to perform tayammum, therefore anyone of my followers can pray wherever the time of a prayer is due."

Taking also into account that the very first Mosque that the Prophet p.b.u.h built in Medina was of earth, the arguments to use this material for the articulation of interiorities of the Mosque would be strengthened also for the fact that rammed earth technique applied in layer creates distinctive patterns as autogenic ornamentation. In this line the ornamentation is integrated with the making process of rammed earth (see Fig. 12).

For Christopher Alexander, ornament arises, naturally, when a person is making something and seeks to embellish this "something" while making it. The embellishing is spontaneous. It comes from the continued unfolding of the whole, going naturally from the broad wholeness of the thing to the microstructure where the chisel, hand, brush, and trowel make patterns in the thing, in order to continue and extend its wholeness.

For the ornament to be profound, the motifs and disposition of the ornament must arise, naturally, from latent centers which are felt within the uncompleted thing.

Our approach seems to be a "flight" against ornament as superfluous and appliqué. Yet, our intention was to create a unique character and atmosphere of the Mosque interior space as $u$ humble space. Moreover, the texture of rammed earth elicits tactile experience.

With the light theme, cool air, reflected water and the Garden of Aden, the phenomenology of architecture is revealed in its whole domain, where phenomenology is performed in the spatial sensuality and tactility of Mosque.

It is the symbolic meaning of earth and light which animates this space and creates the ultimate atmosphere for a livable space where the enactment of prayer takes place.

\subsection{A white Mosque is not a "white elephant"}

Considering the Is lamic principles of simplicity, humbleness, humility and devotion, our approach was not to create a Mosque resembling an arrogant sculpture and a "white elephant" to be feed and praised but never used effectively. In reality the beginning of Is lamic Architecture has been always connected with the time Muslims began to build monumental architecture (Rasdi; 2010), including Mosques as representative buildings. Yet, Prophet p.b.u.h. said: "I was not commanded to build high mosques"

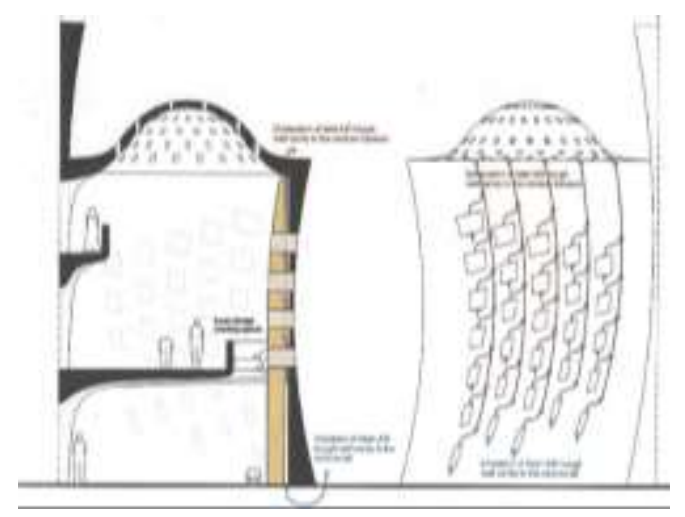

Fig. 18. Section and elevation showing natural ventilation scheme.

\section{Source: Author's drawings}

Earth as a building material, used in our proposal goes hand in hand with the Islamic principles of simplicity, and creating extraordinary performances out of ordinary materials and techniques. Living in an era where the "cheapest survives" (Vincent; 2002) our approach was to use natural materials and principles to construct and run the building. Adopting a structural system of double-shell and cavity for constructing the Mosque, this allowed us to use the cavity in-between two shells - inner and outer-as 
a natural ventilation duct, where fresh air is inhaled form basement through window's sills and the stall air is exhausted through window transoms up into the roof-top. Wall acts as a multi-performative component, from aes thetic performances to structural and technical.

\section{Conclusions}

Being at the same time simple and complex, the Mosque represents one of the most challenging tasks in architectural design for the fact that ontologically it is a "shelter" that bears enormous meanings for the particular user, and as such it is a "container", a medium and a media, where people encode and decode complex social, cultural and material information in order to create a comprehensive system of communication with a sense of belonging to the place and space. When we love a place, we belong to that place and the ordinary becomes extraordinary. Symbolism adds poetic meaning to architecture, moreover this paper has strived to "write" a tangible and tactile poetry through narrative themes in the phenomenology of Mosque architecture.

As a conclusion, this paper bridges the gab between theory and practice in Mosque design, brings other disciplines in an interdisciplinary discourse and cons tructs new bridges between traditional past and the novel future, hence, sets a framework for new design approach on Mosque as a representative building.

\section{References}

1. Akkach, S. (2005) "Cosmology and Architecture in Premodern Islam: an architectural reading of mystical ideas" State University of New York Press, Albany

2. Alexander, Ch. (2004) "The Nature of Order: An Essay on the Art of Building and the Nature of the Universe" Book Three, "A Vision of a Living World" Center for Environmental Structure, Berkeley 3. Al-Hilali, Muhammad Taqi-ud-Din., (trans.) (1999) "Interpretations of the Meanings of The Noble Quran” Darussalam Publications, Riyadh

4. Al-Mundhiri, Al-Hafiz Zakiuddin Abdul-Azim (ed.) (2007) "Sahih Muslim" Darussalam Publications, Riyadh

5. Almusaed, A. (2011) "Biophilic and Bioclimatic Architecture: Analytical Therapy for the Next Generation of Passive Sustainable Architecture" Springer-Verlag, London

6. Arnheim, R. (1977) "The Dynamics of Architectural Form" University of California Press, Los Angeles

7. Bachelard, G. (1994) "The Poetics of Space-the classic look at how we experience intimate places" translated from the French by Maria Jolas, Beacon Press, Boston

8. Day, Ch. (2004) "Places of the Soul: architecture and environment design as healing art" 2nd Ed., Architectural Press, Oxford

9. Douglis, E. (2009) "Autogenic Structures" Taylor \& Francis, Oxon

10. Eliade, M. (1968) "The Sacred and the Profane: The Nature of Religion" A Harvest Book, Harcaurt, Brace \& World, Inc., New York

11. Hasan, A. (trans.) (2008) "Sunan Abu Dawud" Darussalam Publications, Riyadh

12. Holl, S., Pallasmaa, J., Pérez-Gómez, A. (2006) "Questions of Perception: Phenomenology of Architecture" A+U William Stout Publishers, San Francisco

13. Kahera, A., Abdulmalik, L., and Anz, C. (2009) "Design Criteria for Mosques and Islamic Centers: Art, Architecture and Worship" Architectural Press, Oxford

14. Khan, Muhammad Muhsin (trans.) (1997) "Sahih al-Bukhari" Darussalam Publications, Riyadh

15. LaVine, L. (2001) "Mechanics and meaning in architecture" University of Minnesota Press, Minnesota

16. Lawson, B. (2001) "The language of space" Architectural Press, Oxford

17. Layton, M. (2006) "Shape as Memory: A Geometric Theory Of Architecture" Birkhäuser, Basel

18. Le Corbusier (1986) "Toward a New Architecture" Dover Publications, Inc., New York

19. Leach, N. (ed.) (1997) "Rethinking Architecture: A reader in Cultural Theory" Routledge, London

20. Lynch, K. (1960) "The Image of the City" MIT Press, Massachusetts 
21. Minke, G. (2006) "Building with Earth: Design and Technology of a Sustainable Architecture" Birkhäuser, Basel

22. Norberg-Schulz, Ch. (1979) "Genius Loci: Towards a Phenomenology of Architecture" Rizzoli, New York

23. Özkan, S. (ed.) (1996) "Faith and the Built Environment: Architecture and Behaviour in Islamic Cultures" Comportements, Lausanne

24. Prochazka, A. B. (1986) "Architecture of the Islamic Cultural Sphere: MOSQUES" Muslim Architecture Research Program, Zürich

25. Psarra, S. (2009) "Architecture and narrative: The formation of space and cultural meaning" Taylor \& Francis e-Library, New York

26. Puhalla, D. (2011) "Design Elements: Form and Space" Rockport Publishers, Massachusetts

27. Rapoport, A. (1990) "The Meaning of the Built Environment: A Nonverbal Communication Approach" University of Arizona Press, Tuscon

28. Rasdi, M. T. H. M. (2010) "The Design of Mosques as Community Development Centers from the Perspective of the Sunna and Wright's Organic Architecture" Journal of Islamic Architecture, Vol 1, No 1, p. 1-7

29. Schumacher, P. (2011) "The Autopoiesis of Architecture: A New Framework for Architecture" John Wiley \& Sons Ltd.

30. Sheikh, A. (1941) "Muslim Architecture: From the Advent of Islam to the Fall of Mamluk Empire in Egypt" The Academy of Oriental Arts, Lahore

31. Vincent, J. F. (2002) "Survival of the cheapest" materials today, December 2002, p. 28-41

32. Zumthor, P. (1998) "Thinking Architecture" Birkhäuser, Basel 